\title{
COMPARISON ANALYSIS OF SELECTED NUCLEAR POWER PLANTS SUPPLIED WITH HELIUM FROM HIGH-TEMPERATURE GAS-COOLED REACTOR
}

\author{
Natalia Szewczuk-Krypa ${ }^{1}$ \\ Marta Drosińska-Komor ${ }^{1}$ \\ Jerzy Głuch ${ }^{1}$ \\ Łukasz Breńkacz ${ }^{2}$ \\ ${ }^{1}$ Gdansk University of Technology, Poland \\ ${ }^{2}$ Institute of Fluid Flow Machinery, Polish Academy of Sciences, Poland
}

\begin{abstract}
The article presents results of efficiency calculations for two $560 \mathrm{MW}$ nuclear cycles with high-temperature gas-cooled reactor (HTGR). An assumption was made that systems of this type can be used in so-called marine nuclear power plants. The first analysed system is the nuclear steam power plant. For the steam cycle, the efficiency calculations were performed with the code DIAGAR, which is dedicated for analysing this type of systems. The other system is the power plant with gas turbine, in which the combustion chamber has been replaced with the HTGR. For this system, a number of calculations were also performed to assess its efficiency. Moreover, the article names factors in favour of floating nuclear power plants with HTGRs, which, due to passive safety systems, are exposed to much smaller risk of breakdown than other types of reactors which were in common use in the past. Along with safety aspects, it is also economic and social aspect which make the use of this type of systems advisable.
\end{abstract}

Keywords: HTGR, nuclear power plants, floating marine plants, nuclear power

\section{INTRODUCTION}

In March, 2011, an earthquake with magnitude of $9 M_{w}$ occurred in the north eastern part of Japan. Then the tsunami, formed as a result of most intensive tectonic movements in this area in recent 140 years, destroyed the east coast of Japan, killing nearly 20000 people and demolishing nearly 350000 homesteads. Among other objects, it was the Fukushima Daiichi nuclear power plant which was badly hit by the tsunami. Its damage resulted in loss of control over one of power plant blocks in operation, which further led to the leakage of radioactive substances to the environment $[12,6]$. The nuclear disaster caused by forces of nature in the Fukushima Daiichi power plant has launched a public discussion over the risk of use of nuclear energy. Despite safety concerns, the energy extracted from the atom, due to its advantages, is commonly believed to be difficult to replace by other well-known fossil energy resources. These advantages undoubtedly include infinitesimal emission of carbon dioxide during the entire lifetime of nuclear power plant. Moreover, the nuclear fuel is relatively cheap, compared to other available energy resources [8]. That is why, instead of resigning from the use of nuclear energy, it is advisable to improve the operational safety of installations supplied with nuclear fuels. A solution which will reduce the risk of damage of a nuclear power plant due to, for instance, earthquake, tsunami, or another natural disaster, consists in moving such a system from land far into the ocean [9].

Although initial concepts to make use of nuclear energy concerned its marine applications, it is inland production units which are dominating in its use now. Until the beginning of the 21st century, marine nuclear energy was mainly used for military purposes [2]. Only a small number of civilian ships with nuclear drive were built, including NS Savannah, Otto Hahn, Mutsu, and Russian icebreakers, the Yamal for instance [5]. Although nuclear systems are not very popular as off-shore solutions, attempts are made to build marine nuclear 
power plants. Here, the Americans and Russians are believed to be precursors of this type of solutions. The first floating power plant supplied with nuclear fuel was built in the USA. The electric power of this plant was $10 \mathrm{MW}(\mathrm{e})$. It was used in the US military base situated in the Panama Canal [4]. The Russians, on the other hand, are the authors of the first nuclear power plant built for civilian purposes. Since nearly 50\% of Russian territory is situated in the far north, this country faces the problem of electric power delivery to places where natural conditions are extremely severe, which makes building inland infrastructure and production units extremely difficult [13]. Hence, attempts are made to develop alternative energy sources. In this context, marine nuclear power plants can operate well in difficult circumpolar conditions, as these systems do not require elaborate infrastructure. Moreover, they can be operated for long time without reactor re-fuelling, which seems to be very favourable in far north conditions, in both economic and logistic terms $[14,10]$. The next country which follows the USA and Russia is China. Due to smog problems, the government of China has made a decision to create as many sources of alternative energy as possible. This list includes nuclear power plants situated far from inhabited territories, which well corresponds with the idea of floating production units. Hence, there are plans to build in the nearest future a fleet of more than 20 units of this type. These systems are expected to ensure stable delivery of energy for projects carried out on the South China Sea (for instance, power supply for drilling platforms).

There are also other favourable aspects concerning the use of marine systems for electric energy production which are worth analysing. In the time of overpopulation and large worldwide need for food production, all areas which can be developed are of great value. This leads to the dilemma whether it is worthwhile to use next valuable territories for building power objects on them. This problem becomes particularly important on islands, where the growth of population enforces the use of each free patch of land for development of residential and agricultural areas. When analysing nuclear solutions, the landscape aspect is also of some importance. Power islands can be successfully used in tourist regions, in which the elaborate structure used for energy production would distort the landscape and discourage potential visitors.

A popular type of reactor which could be successfully used in nuclear power plants situated on sea is the hightemperature gas-cooled reactor (HTGR). First reactors of this type were built in the 1970s but were not introduced to common use for economic reasons. At present, they attract strong interest and many research activities are in progress to improve the efficiency and safety of the newly designed high-temperature reactors. The HTGRs make use of gravel deposit. The reactor itself has the shape of a cylinder filled with triple coated isotropic fuel (TRISO). This fuel has the form of small graphite balls filled with fissile material of $0,5 \mathrm{~mm}$ in diameter, which usually is low-enriched uranium oxide $[1,7]$. The greatest advantage of HTGRs is their high safety of operation.
After the failure, the fuel can only be emptied from the reactor with the aid of passive systems making use of natural force of gravity. What is noteworthy, this action can be undertaken even when there is no power supply to the nuclear power block. Moreover, if helium is used as cooling agent in the system, its leakage will not lead to environment contamination, since helium as noble gas is chemically inert and is not radioactively activated, while all radioactive products of nuclear reaction remain tightly locked in fuel balls. HTGRs are characteristic for very high level of fuel burnup [7], which is great economic advantage. Moreover, the amount of generated radioactive waste is small. This aspect is of high importance for off-shore power plants. High fuel burnout allows the fuel to be used longer, and consequently, fuel deliveries to keep the plant operate can be less frequent. Smaller amounts of radioactive waste are desirable due to space limits.

\section{AIM OF WORK}

The article presents two nuclear power plants which can be used for energy production on so-called power islands and compares their efficiency. Both systems cooperate with the HTGR. A substantial part of the article is presentation of numerical calculations. For one of these systems, the calculations were made with the code DIAGAR, which is a helpful tool in calculations concerning systems with steam turbine.

\section{DESCRIBING OBJECT OF EXAMINATION}

The first analysed system is the steam turbine cycle supplied with the energy obtained in the high-temperature helium-cooled reactor (Fig.1).

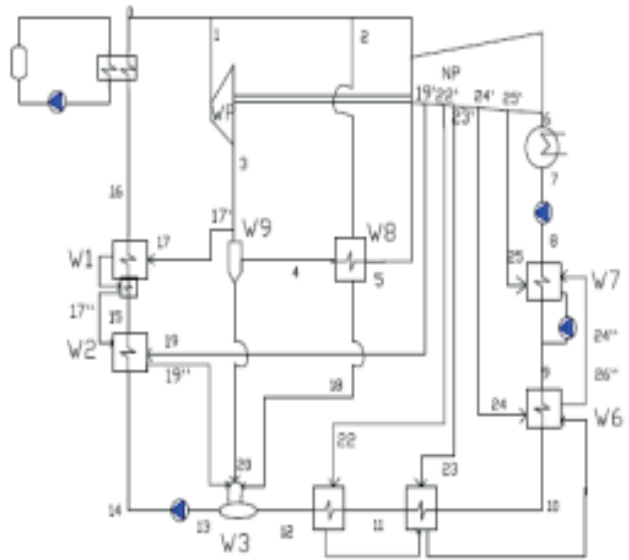

Fig.1. Scheme of steam cycle supplied from HTGR

The cycle has been designed for power of $560 \mathrm{MW}$. The assumed temperature of live steam is $600^{\circ} \mathrm{C}$. This value results from the amount of heat which can pass from the cooling medium to water in the steam cycle. The initial pressure of live 
steam is 285 bars. In the analysed cycle, seven regenerative heat exchangers are used, the task of which is to increase the temperature of working medium at steam generator inlet. This procedure significantly improves the system efficiency. The regenerative heat exchangers are supplied with the steam taken from regenerative extraction points in the turbine bodies. One of these exchangers which are used in the system is deaerator. Moreover, an interstage steam superheater and a moisture separator are also used. These two solutions increase the dryness degree in last stages of the low-pressure (LP) turbine, which results in the improvement of operating safety and better efficiency of the turbine being part of the cycle.

The other analysed object is the gas turbine cycle with recuperation (Fig.2.). In this case the combustion chamber has been replaced with the HTGR. The applied recuperation makes it possible to use the waste heat of the medium at gas turbine exit for heating the medium at reactor inlet. This procedure improves the efficiency of the system. The cooling medium is helium ( $\mathrm{He})$, due to its favourable physical characteristics. Helium reveals 5-6 times as high thermal conductivity as other gases: air, nitrogen, or carbon dioxide. Consequently, the smallest dimensions of heat exchangers and the reactor itself can be obtained, compared to other cooling media commonly used in reactors.

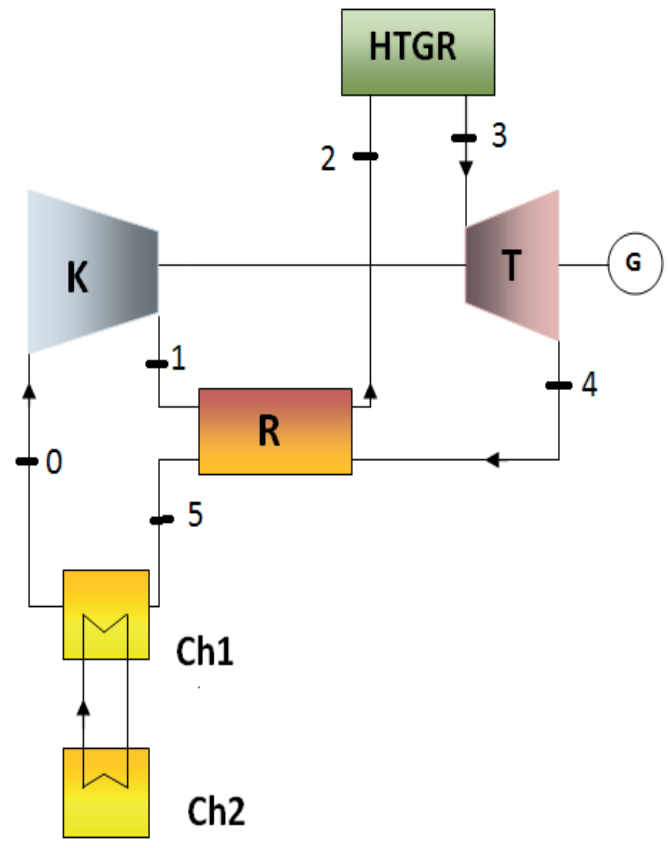

Fig.2. Scheme of gas cycle with HTGR and recuperation. $K$ - compressor, $R$ - recuperator, HTGR - high-temperature gas-cooled reactor, $T$ - gas turbine, G-generator, Ch1, Ch2 - coolers.

\section{METHODOLOGY OF CALCULATIONS}

For calculating purposes, a scheme of the analysed steam cycle supplied from HTGR is created in the software Projdiag, dedicated for creating numerical schemes of thermal cycles.
In this case the structure of the analysed cycle (Fig.3.) consists of individual elements and connections between them. Each element corresponds to one apparatus composing the steam cycle. In the next step, the scheme is introduced to the code DIAGAR used for steam cycle calculations. For this purpose, the code makes use of graph theory to relate thermodynamic and flow parameters of the cycle with characteristics of apparatuses and their geometry.

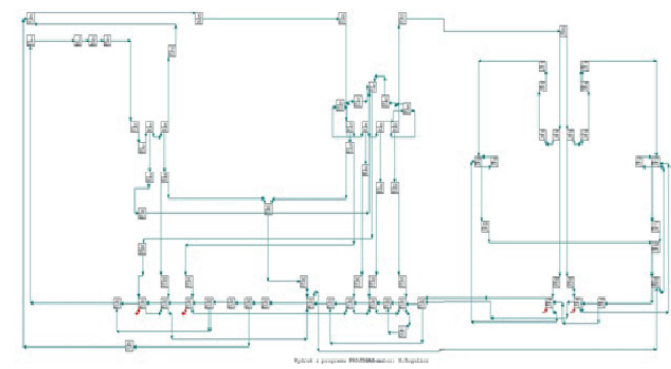

Fig.3. Numerical scheme of cycle created in numerical software Projdiag

The input data for DIAGAR are numerical schemes and geometric data of apparatuses, as well as independent parameters (Fig.4.), understood as autonomous quantities which are not affected by changes of other system parameters. In the analysed case, the list of independent parameters includes: power, live steam pressure, superheated steam temperature, flow rate, inlet temperature, and exit pressure. This way of assignment of the above parameters makes it possible to use the Stodola-Flugel equation in the code. The list of dependent parameters in the code includes: pressure, temperature, mass, specific enthalpy, specific entropy, and volume - numerically calculated based on independent variables [3]. The results of DIAGAR calculations can be used as simulators for physical processes and for obtaining diagnostic thermal-flow relations. In that case, the result of code operation is elementary heat consumption, cycle efficiency, and efficiency of electric energy generation.

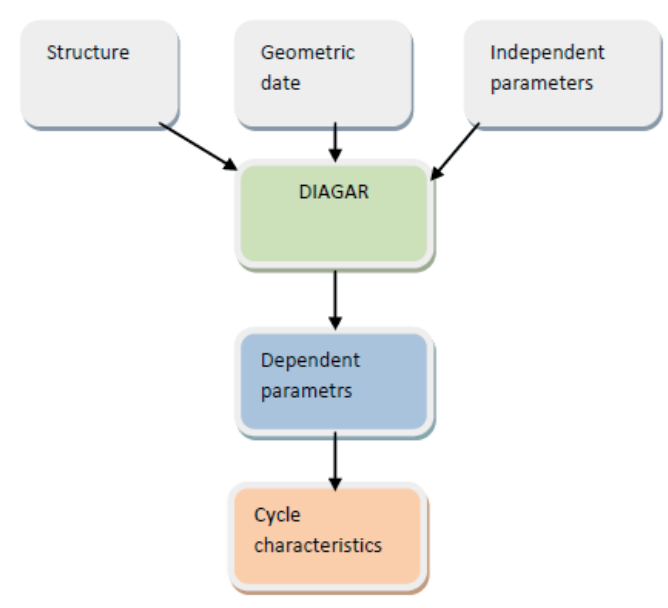

Fig.4. DIAGAR operation scheme 
A series of simulations were performed for the steam cycle cooperating with high-temperature helium-cooled reactor. These simulations based on numerical results obtained from DIAGAR and their task was to optimise the condenser pressure in such a way as to reach the value corresponding to maximum cycle efficiency. The condenser pressure was changed from 0.03 to $0 ., 1$ bar, with step equal to 0,01 bar. As already mentioned, the assumed power of the cycle was $560 \mathrm{MW}$. The mass flow rate corresponding to this power was assumed to be equal to $370 \mathrm{~kg} / \mathrm{s}$. As a result of the simulation, the values of net and gross efficiency were obtained. The gross efficiency value was related to elementary heat consumption (1), while the net efficiency, taking into account own demands of the steam turbine power plant, was approximately smaller by $9 \%$ than the gross efficiency (2).

$$
\begin{gathered}
\eta_{\text {brutto }}=\frac{3600}{\text { Unit Heat Consumption }} * 100 \\
\eta_{\text {netto }}=91 \% * \eta_{\text {brutto }}
\end{gathered}
$$

The parameters of the gas cycle with HTGR (Tab.1.) were determined taking mainly into account the requirements of the reactor. The helium pressure at reactor inlet was assumed at the level of 70 bar. This pressure $p_{2}$ is required for correct operation of HTGR and takes into account limitations concerning the cooling medium volume. When this volume is excessively large, it results in oversizing the heat exchangers and the reactor itself, with further negative effect on the economic efficiency of the system. To ensure correct medium pressure at reactor inlet, an assumption was made, taking into account the lower temperature $t_{1}$ and pressure $p_{1}$ of the medium in the cycle, that the compression $\pi_{K}$ of the compressor is at the level of 2,27 [-]. In the preliminary calculations it was assumed that HTGR heats helium to the upper temperature $t_{3}=1223 \mathrm{~K}$, while in further calculations the cycle efficiency was optimised with respect to this temperature. For optimisation purposes, the temperature $t_{3}$ was allowed to vary from about $1073 \mathrm{~K}$ to $1273 \mathrm{~K}$ [15]. It was also assumed that medium expansion in the turbine reaches a slightly higher pressure than that recorded at compressor inlet. This assumption took into account the fact that helium, after leaving the gas turbine, flows through a recuperator and a cooler, which contributes to small medium pressure losses. To meet the above assumptions, the turbine compression $\pi_{K}$ was assumed to be equal to 2,5 [-]. For helium as cooling medium, the specific heat $\mathrm{cp}$ was assumed to keep a constant value equal to $5,19 \mathrm{~kJ} / \mathrm{kgK}$, regardless of medium temperature, while the adiabatic exponent was assumed equal to 1,66 [-].

The numerical calculations were performed based on the assumed values of compression and cooling medium temperature behind the HTGR. The calculations made use of the adiabatic equations to determine isentropic parameters for the compressor and turbine in the system. Real work of these devices was calculated based on theoretical efficiency values. The compressor efficiency $\eta_{K}$ was assumed at the level of $85 \%$, while the gas turbine efficiency $\eta_{T}$ at the level of $90 \%$. The working medium temperatures behind and in front of the recuperator were calculated based on the theoretical value of recuperator efficiency $\eta_{R}$ equal to $85 \%$. For the assumed values, thermodynamic parameters were calculated at characteristic points, along with the efficiency of the entire cycle. The cycle efficiency was optimised with respect to different values of cooling medium temperature $T_{2}$ behind the reactor. For calculation purposes, the characteristics of helium ( $\mathrm{He}$ ) as cooling medium were assumed not to depend on temperatures and pressures recorded in individual system elements. Both the specific heat $\mathrm{cp}$, and the adiabatic exponent were assumed constant. This assumption was made based on the analysis of changes of medium parameters in relation to changing conditions of the environment in which the medium worked.

\section{Tab.1. Thermodynamic parameters calculated at characteristic points of the cycle for assumed values of compression and cooling medium

\begin{tabular}{|c|c|c|c|}
\hline \multicolumn{4}{|l|}{ Parameters of gas cycle with HTGR } \\
\hline Gas turbine power & $\mathrm{Ne}$ & 560 & MW \\
\hline Medium pressure at compressor inlet & p0 & 2,8 & $\mathrm{MPa}$ \\
\hline Medium temperature at compressor inlet & T0 & 299,15 & $\mathrm{~K}$ \\
\hline Medium enthalpy at compressor inlet & i0 & 1552,59 & $\mathrm{~kJ} / \mathrm{kg}$ \\
\hline Medium pressure at compressor exit & p1 & 70 & bar \\
\hline Medium temperature at compressor exit & $\mathrm{T} 1$ & 453,83 & $\mathrm{~K}$ \\
\hline Medium enthalpy at compressor exit & i1 & 2355,4 & $\mathrm{~kJ} / \mathrm{kg}$ \\
\hline Medium pressure at HTGR inlet & $\mathrm{p} 2$ & 70 & bar \\
\hline Medium temperature at HTGR inlet & $\mathrm{T} 2$ & 837,94 & K \\
\hline Medium enthalpy at HTGR inlet & $\mathrm{i} 2$ & 4348,9 & $\mathrm{~kJ} / \mathrm{kg}$ \\
\hline Medium pressure behind HTGR & p3 & 68 & bar \\
\hline Medium temperature behind HTGR & T3 & 1223 & K \\
\hline Medium enthalpy behind HTGR & i3 & 6348,15 & $\mathrm{~kJ} / \mathrm{kg}$ \\
\hline Medium temperature at gas turbine exit & $\mathrm{T} 4$ & 917 & K \\
\hline Medium pressure at gas turbine exit & $\mathrm{p} 4$ & 30 & Bar \\
\hline Medium enthalpy at gas turbine exit & $\mathrm{i} 4$ & 4759 & $\mathrm{~kJ} / \mathrm{kg}$ \\
\hline
\end{tabular} temperature behind HTGR}

The performed calculations aimed at assessing the efficiency of the gas cycle with high-temperature heliumcooled HTGR reactor. The efficiency was optimised with respect to cooling medium temperature behind HTGR.

The cycle efficiency was calculated from equation 3:

$$
\eta=\frac{N_{e T G}}{Q_{d H T G R}}=\frac{N_{T G}-N_{K}}{Q_{d H T G R}}
$$

where:

$\eta$ - efficiency of gas cycle with HTGR

$N_{\text {eTG }}$ - power output of the system

$Q_{d H T G R}$ - heat taken by cooling medium from HTGR

$N_{T G}$ - gas turbine power

$N_{K}$ - compressor power 


\section{RESULTS}

The results of numerical calculations performed for the steam cycle made a basis for determining the relation between the condenser pressure pk and gross efficiency of the cycle. (Fig.5.)

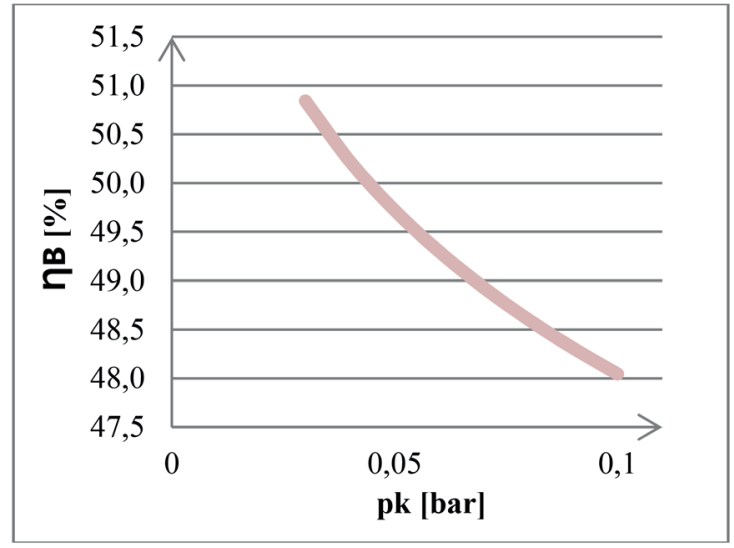

Fig.5. Gross efficiency $\eta_{B}$ vs. condenser pressure $p k$

Based on formula (2) and gross efficiency values, the net efficiency of the steam cycle supplied from HTGR was determined. The calculated net values were used for creating the relation shown in (Fig.6.)

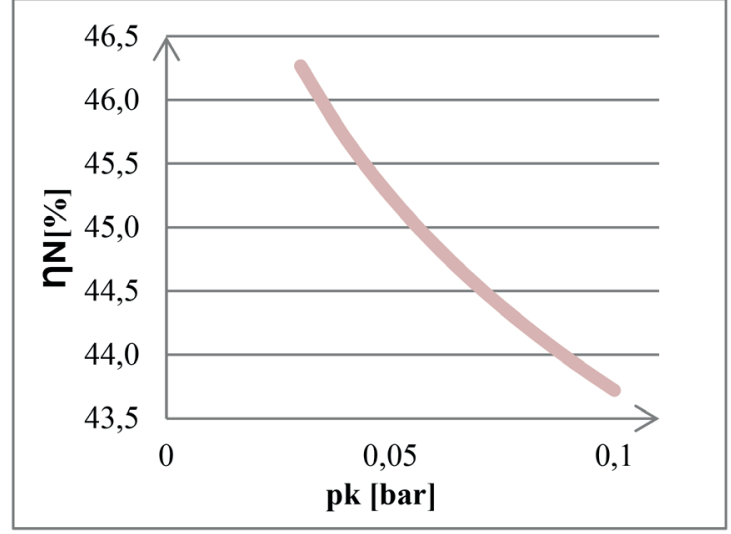

Fig.6. Net efficiency $\eta_{B}$ vs. condenser pressure $p k$

These characteristics reveal that the increase of condenser pressure leads to the decrease of system efficiency. The optimal condenser pressure value equals 0,03 bar. The difference between the highest and lowest pressure values, which is equal to 0,7 , causes the decrease of net efficiency by $2,545 \%$, and gross efficiency by $2,797 \%$. These efficiency losses increase the operating costs due to higher fuel consumption. In the case of nuclear power plants, of high importance is the cost of spent nuclear fuel storage. That is why greater amount of consumed nuclear fuel is unprofitable in economic terms.

Based on numerical calculations, the relation between the efficiency of the analysed gas cycle and the cooling medium temperature behind HTGR was determined. This temperature was assumed within the range of temperatures available in the HTGR type reactor. The highest efficiency was obtained for the working medium temperature equal to $1000\left[{ }^{\circ} \mathrm{C}\right]$. The created characteristic (Fig.7.) is consistent with expectations based on the knowledge about gas turbine cycles. These expectations say that the increase of medium temperature behind the combustion chamber, or another source of heat, should lead to the increase of system efficiency.

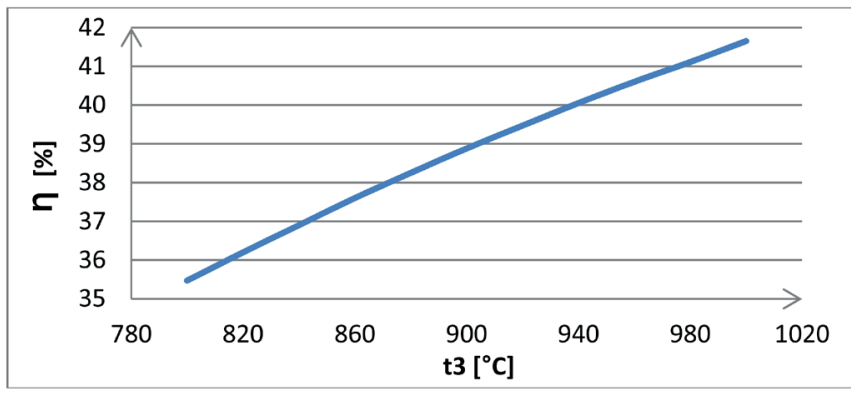

Fig.7. Efficiency of gas cycle with HTGR vs. working medium temperature at reactor exit

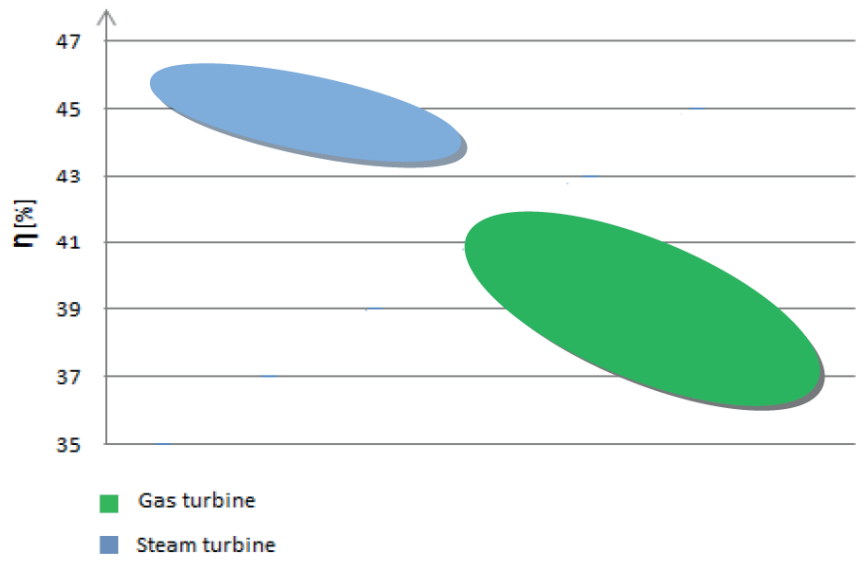

Fig.8. Efficiency ranges of compared systems

\section{CONCLUSIONS}

When analysing the results of numerical calculations for two selected variants of nuclear systems with hightemperature gas-cooled reactor (HTGR), the following conclusions can be drawn:

- Comparing the nuclear steam cycle and the nuclear gas cycle, both of the same power of 560MW (Fig.8.), we can easily notice that the system with steam turbine has much higher efficiency than the gas system. The net efficiency of the steam power plant varies from $43,7 \%$ to $46,3 \%$, while for the gas power plant it is within $35,5 \%$ to $41,7 \%$.

- The increase of condenser pressure provokes the efficiency decrease of the nuclear steam cycle. The highest efficiency of the analysed cycle was obtained for the condenser pressure equal to 0,03 bar. In this case the gross efficiency was equal to $50,84 \%$. Increasing the condenser pressure to 0,1 bar resulted in the efficiency loss approximately amounting to $2,8 \%$, which in the case of high-power 
steam systems is equivalent to significant worsening of economic indices of system operation, due to much higher expenditures on fuel for the reactor.

- The observed high efficiency values of steam cycle could be mainly obtained due to the use of interstage superheater and regenerative heat exchangers. These two measures significantly improve the efficiency of steam systems.

- In the case of the gas system with HTGR, the system efficiency increase was obtained by increasing the working medium temperature at reactor exit. For optimisation purpose, this temperature was allowed to vary from $1073 \mathrm{~K}$ to $1273 \mathrm{~K}$, depending on possibilities of HTGR. Within this temperature range, the cycle efficiency took values from about $35,5 \%$ to about $41,7 \%$.

- The efficiency of the gas system is highly affected by the use of the recuperator, thanks to which the heat of the exhaust gas can be additionally used for heating the working medium at reactor inlet. Consequently, less fuel is needed to obtain the required medium parameters at turbine inlet, which is reflected in measurable increase of system efficiency.

- In fact, decision making about selection of technology to be used in given conditions is a complex process, which is affected by numerous aspects concerning economy, safety (of utmost importance), as well as political and social issues. Indeed, the efficiency of the analysed systems is also the aspect which is taken seriously into account when making such a complex decision.

Due to their advantages, high-temperature gas-cooled reactors can be successfully used in marine nuclear power plants, either as steam or gas variants. Marine production units can become an ideal solution for areas with severe natural conditions, which make developing transporting infrastructure very difficult. Such areas may include, for instance, islands, or densely populated areas with poor water resources (insufficient for cooling purposes). Offshore nuclear systems can also be advantageous in safety terms. Unlike inland power plants, marine production units will be much less exposed to damage or destruction caused by such natural disasters as earthquake, tsunami or flood.

\section{BIBLIOGRAPHY}

1. Baek J-K., Mistarihi Q., Yeo S., et al.: A Preliminary Study for Diffusion Experiments of Metallic Fission Products in Graphite for HTGR. Transaction of the Korean Nuclear Society Autumn Meeting Gyeongiu, Korea, October 29-30, 2015

2. Carlton J S., Smarta R., Jenkins V.: The nuclear propulsion of merchant ships: Aspects of engineering, science and technology. Journal of Marine Engineering \& Technology 2011, pp. 47-59

3. Gardzilewicz A., Głuch J., Bogulicz M. (1994): DIAGAR manual for turbine set No. 3 at Kozienice Power Plant (in Polish). Maszyny Przepływowe, Sp. z o.o., Report no. 19/9
4. Gorlinski Yu.E., Kut'kov V.A, Lystsov V.N., et al.: Securing the radiological safety of people and the environment at all stages of the life cycle of floating nuclear heat-and-power plants. Atomic Energy Vol. 107, No. 2, 2009, pp. 122-129

5. Hirdaris, S.E.; Cheng, Y.F.; Shallcross, P.; Bonafoux, et al.: Considerations on the potential use of Nuclear Small Modular Reactor (SMR) technology for merchant marine propulsion. Ocean Engineering Vol. 79, 2014, pp. 101-130.

6. Hirose, K.: 2011 Fukushima Dai-ichi nuclear power plant accident: Summary of regional radioactive deposition monitoring results. Journal of Environmental Radioactivity, 2012, pp. 13-17.

7. Kowalczyk T., Głuch J., Ziółkowski P.: Analysis of possible application of high-temperature nuclear reactors to contemporary large-output steam power plants on ships. Polish Maritime Research, 2016 Vol. 23, No. 2 (90), pp. 32-41

8. Lee K., Lee K-H., Lee J., et al.: A new design concept for offshore nuclear power plants with enhanced safety features. Nuclear Engineering and Design 254 2013, pp. 129-141

9. Lee K-H., Kim M-G., Lee J-I., Lee

10. P-S.: Recent Advances in Ocean Nuclear Power Plant, Energies, 2015, Vol 8 pp. 11470-11492

11. Lepekhin A., Andreeva-Andrievskaya L., Kuznetsov V.: Status of Russian small and medium sized reactor activities. In Proceedings of the Meeting of the International Framework for Nuclear Energy Cooperation, Rome, Italy, 6 December 2010

12. McDonald C.F.: A nuclear gas turbine perspective: The indirect cycle (IDC) offers a practical solution, Proceedings of the 31. intersociety energy conversion engineering conference. Volume 2: Conversion technologies, electro-chemical technologies, Stirling engines, thermal management

13. Nagatani K., Kiribayashi S., Okada Y. et al.: Emergency response to the nuclear accident at the Fukushima Daiichi Nuclear Power Plants using mobile rescue robots. Journal of FIELD ROBOTICS Vol. 30, Issue 12013 , pp. 44-63

14. Sarkisov A. A., Vysotskii V. L., Bilashenko V.P., at al.: Expected radiological and radioecological consequences of operating floating nuclear heat and power plants. Atomic Energy Vol. 104, No. 3, 2008, pp. 237-248

15. Standring W.J.F, Dowdall M., Amundsen I., Strad P.: Floating nuclear power plants: Potential implications for radioactive pollution of the northern marine environment. Marine Pollution Bulletin, 58, 2009, pp.174-178 
16. Takamatsu K., Hu R.: New reactor cavity cooling system having passive safety features using novel shape for HTGRs and VHTRs. Annals of Nuclear Energy, 77, 2015, pp. 165-171

\section{CONTACT WITH THE AUTHORS}

Marta Drosińska-Komor

e-mail:mardrosi@pg.edu.pl

Natalia Szewczuk-Krypa

e-mail: natszew1@pg.edu.pl

Jerzy Głuch

e-mail:jgluch@pg.edu.pl

Faculty of Ocean Engineering and Ship Technology

Gdańsk University of Technology

11/12 Narutowicza St.

80-233 Gdansk

Poland

Łukasz Breńkacz

e-mail:lbrenkacz@imp.gda.pl

Energy Conversion Department

Institute of Fluid Flow Machinery

Polish Academy of Sciences

14 Fiszera St.

80-231 Gdansk

Poland 